\title{
Exergetic, Exergoeconomic and Exergoenvironmental Analysis of Intercooled Gas Turbine Engine
}

\author{
$1^{1^{*}}$ Abdulrahman Almutairi, ${ }^{2}$ Pericles Pilidis, ${ }^{3}$ Nawaf Al-Mutawa \\ 1,2 Cranfield University, School of Engineering, Power and Propulsion Department \\ Cranfield, Bedfordshire MK43 OAL, UK \\ ${ }^{3}$ Kuwait University, College of Engineering and Petroleum, Mechanical Engineering Department \\ Alkhalidiya, P.O.Box 5969 Safat 13060, Kuwait \\ *E-mail: a.s.almutairi@cranfield.ac.uk
}

Keywords: Exergy, Intercooled, Gas Turbine, Exergoeconomic and $\mathrm{CO}_{2}$ emission

\begin{abstract}
Exergetic and exergoeconomic and exergoenvironmental analyses have been performed for an advanced aero-derivative intercooled gas turbine engine. The proposed system was modelled using the IPSEpro software package and validated using manufacturer's published data. The exergoeconomic model evaluates the cost-effectiveness of the gas turbine engine based on the Specific Exergy Costing [SPECO] method. The $\mathrm{CO}_{2}$ emissions per KWh were estimated using a generic combustor model, HEPHAESTUS, developed at Cranfield University. It is well known that the exergetic analysis can determine the magnitudes, locations and types of losses within an energy system. The effect of load and ambient temperature variations on gas turbine performance were investigated for two different configurations. The first system, Case-I, was a simple gas turbine (SCGT) engine, and the second, Case-II, an intercooling gas turbine (ICGT) system. The latter enhances gas turbine efficiency but, at the same time, has an adverse effect on the combustion chamber due to reduced compressed air temperature. It was confirmed that full load and low ambient temperature are preferable due to the low waste exergy. The unit exergy cost rate for both SCGT and ICGT have been calculated as 8.59 and $8.32 \mathrm{US} \$ / \mathrm{GJ}$ respectively. The exergoenvironmental results show the ICGT achieved lower emission levels and is more environmentally friendly than the SCGT.
\end{abstract}

\section{Introduction}

Gas turbines are an attractive choice for power application worldwide due to their low installation cost, short installation time, operational flexibility and ability to integrate with other thermal energy systems and, thus, the most suitable prime mover for multipurpose systems [1]. Thermal energy systems consume vast amounts of natural and 
economical resources, which contribute substantially to the climate change problem. The gas turbine engine will be an important factor in determining energy generation, until at least 2050 [2], and thus the development of gas turbine technologies which improve the efficiency of operation, and reduce costs and emissions per unit output, are a great challenge facing researchers and manufacturers.

Exergy analysis can determine the deficiencies of energy systems by quantifying the entropy-generation of all components based on the first and second laws of thermodynamic [3]. Furthermore, exergoeconomic methodology is a useful tool that combines the concepts of exergy and economics to evaluate the cost-effectiveness of the thermal system. The cost of inefficiencies can be measured and evaluated, and hence can be reduced, which is helpful for designers and operators. Tsatsaronis [4] first suggested the term exergoeconomic, when he combined exergy with economic analysis. Today, many researchers use exergoeconomics in their study of different thermal applications such as [5]-[8]. Wang et al. [9] conducted an exergoeconomic analysis of ultra-supercritical power plant located in china using SPECO. The study introduced a number of solutions to enhance the power plant's cost-effectiveness. Ameri et al. [10] carried out exergoeconomic analysis for the Hamedan steam power plant. They found that the highest exergy destruction cost took place in the boiler followed by the turbine. Kwak et al. [3] analyzed a combined cycle power plant (CCPP) using the exergy-costing method to estimate the power output unit costs, and developed a computer program to calculate the unit cost of products based on capital cost, salvage values and maintenance costs of each component. Kwon et al. [11] performed an exergoeconomic analysis using two different methods for a cogeneration system based on gas turbines. The proposed model, was initially introduced by Bejan et al. [12], and is known as the CGAM problem. This study concludes that component annualized costs significantly effect the product unit cost.

Turan and Aydin [13] recently introduced an exergoeconomic analysis of an aeroderivative gas turbine engine using a levelized cost method. Their results show the exergy cost rate and unit cost rate for all streams in an LM6000 gas turbine engine, calculated using actual data.

Many reports in the literature have analyzed the thermal process using a combined exergy and environmental approach to minimize environmental impact. Ahmadi et al. [14] applied exergy, exergoeconomic and environmental impact analysis to several 
CCPPs and demonstrated that the combustion chamber was the major exergy destructor in CCPPs, and a minimized fuel flow rate will reduce product cost as well as $\mathrm{CO}_{2}$ emission. Petrakopoulou et al. [15] investigated three oxy-fuel plants, including $\mathrm{CO}_{2}$ capture, using exergoeconomic and exergoenvironmental methods. A conflict was found between the economic and environmental assessments, making the optimal selection of plant subject to the specific concerns of the decision-maker.

However, while the literature contains numerous studies of different thermal systems, no-one has yet explored an advanced aero-derivative gas turbine engine using exergetic methodology and compared the results with a real set of data. This article describes a study in which exergetic, exergoeconomic and exergoenvironmental analyses were performed on an intercooled advanced aero-derivative engine turbine and on a hypothetical model without an intercooling system. The study aimed to:

1. Explore the effects of intercooling on exergy destruction for all components.

2. Investigate the effects of load variation and ambient conditions on the proposed system.

3. Apply exergoeconomic and exergoenvironmental analyses to an advanced energy system.

\section{Case Study}

In this study, an ICGT engine and hypothetical model of a SCGT engine without intercooling were investigated. The ICGT engine is based on the LMS $100 \mathrm{GE}$, a stateof-the-art aero-derivative gas turbine, see Figure 1.

Intercooling is a technique that increases power by reducing compressor power consumption. With an intercooling system, the power consumption of the high-pressure compressor (HPC) is reduced, which results in a high pressure ratio and increased efficiency.

The ICGT engine is distinguished by modification of the intercooling of the gas turbine system, and in today's market, it has the highest power output and thermal efficiency for aero-derivative simple cycles. The ICGT system consists of three shafts, as illustrated in Figure 1. The first shaft is connected to the low-pressure components; the 
second to the high-pressure components; and the third to the power turbine. The cold section spans the low-pressure compressor (LPC), the high pressure compressor (HPC), and the intercooler between them. Compressed air is delivered from the LPC to the intercooler to reduce the inlet temperature to the HPC. The work required by the HPC will be reduced, leading to increased engine output power. One negative impact of the intercooling process is a lower temperature delivered to the combustor, which increases engine fuel consumption. The overall pressure ratio in the LPC and HPC compressors is 42. There are two scroll cases to reduce pressure loss one at the exit of the LPC before the intercooler, and the second at the inlet of the HPC. The high-pressure compressed air moves forward to the annular combustor and mixes with fuel to yield hot gases. These gases are directed into the turbine section and expand in the high-pressure turbine (HPT), the intermediate-pressure turbine (IPT), and the low-pressure turbine (LPT) or power turbine (PT). The HPT and IPT are derived from the HPC and LPC, whereas the LPT produces the power output. The thermal efficiency and capacity of the ICGT engine is about $45 \%$ and $100 \mathrm{MW}$, respectively, under International Standards Organization [ISO] conditions. The stream of exhaust gases exits from the stack at atmospheric pressure and a temperature of $685 \mathrm{~K}$. ICGT performance data are listed in Table 1.

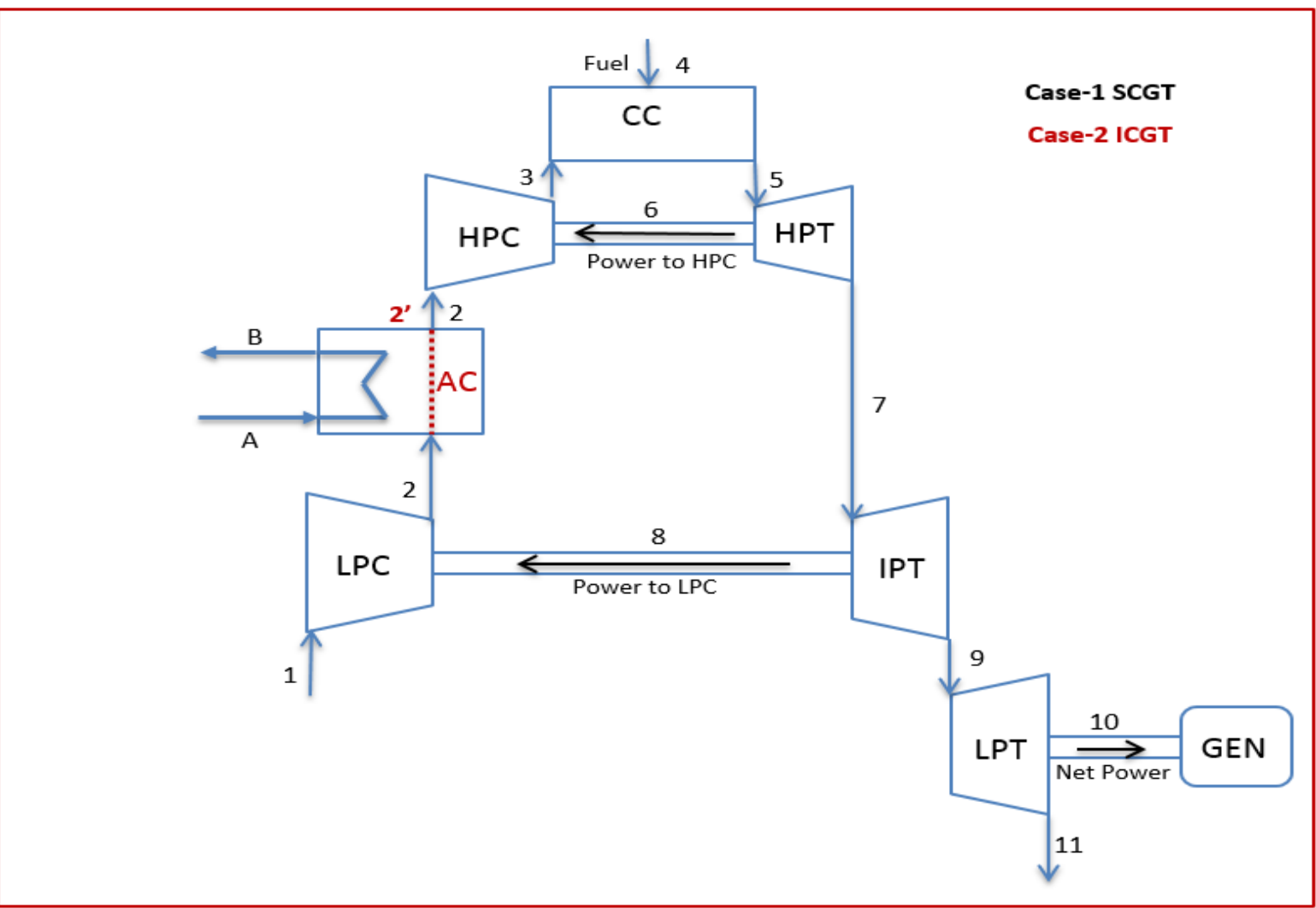

Figure 1. Schematic diagram of the SCGT and ICGT. 
Table 1. Performance data of ICGT system at ISO condition.

\begin{tabular}{|c|l|c|c|}
\hline \multicolumn{2}{|c|}{ Description } & Value & Unit \\
\hline \multirow{4}{*}{} & GT Power output & $\mathbf{9 8 . 7 0}$ & MW \\
\cline { 2 - 4 } & Thermal efficiency & $\mathbf{4 5}$ & $\%$ \\
\cline { 2 - 4 } & Heat rate & $\mathbf{7 9 2 1 . 0 0}$ & $\mathbf{k J} / \mathbf{k W h}$ \\
\cline { 2 - 4 } & Compressor Pressure ratio & $\mathbf{4 2}$ & $\cdots$ \\
\cline { 2 - 4 } & Exhaust Mass flow & $\mathbf{2 2 2}$ & $\mathbf{K g} / \mathbf{s}$ \\
\cline { 2 - 4 } & Exhaust Temperature & $\mathbf{4 1 2}(\mathbf{6 8 5})$ & ${ }^{\circ} \mathbf{C}(\mathbf{K})$ \\
\hline
\end{tabular}

\section{Methodology}

In the present study, the performance of the proposed systems was examined at three loads: $50 \%, 75 \%$ and $100 \%$. Three values of ambient temperature was used at each load: $288 \mathrm{~K}, 305 \mathrm{~K}$ and $323 \mathrm{~K}$. The environmental state was chosen as $288 \mathrm{~K}$ and ambient pressure of 1.013 bar. Further assumptions included in the gas turbine model were:

- The gas turbine models operated at a steady state.

- An ideal gas mixture concept was applicable in both air and combustion products.

- Gas leakage was negligible.

- The kinetic and potential energies of fluid streams were negligible.

- The combustion reaction was complete and $\mathrm{N}_{2}$ was inert.

- The supplied fuel is natural gas.

- Heat transfer loss from the combustor was $2 \%$ of the natural gas lower heating value (LHV)

\subsection{Energy Analysis}

Energy analysis based on the first law of thermodynamics can be used to evaluated the performance of any energy system; the sum of all the energies in a closed system is constant. The general energy balance equation at steady state conditions can be expressed as:

$$
\dot{Q}-\dot{W}=\Delta \mathrm{H}+\Delta \mathrm{KE}+\Delta \mathrm{PE}
$$


The net energy transfers either by heat or work is represented by the left-hand side of Equation (1), while the right-hand side shows the rate of change in enthalpy, kinetic and potential energy respectively.

\subsection{Exergy Analysis}

The exergy is called also availability, which represents the maximum useful work that could be extracted through driving the system from a given state to a state of equilibrium with the environment. The exergy analysis can quantify and identify the consumption exergy sources due to irreversibilities and losses during the transition to the environmental state. The exergy, $\dot{E}_{x}$, consists of the sum of four distinct components: $\dot{E}_{p h}$ physical exergy, $\dot{E}_{c h}$ chemical exergy, $\dot{E}_{k e}$ kinetic exergy and $\dot{E}_{p e}$ potential exergy. The total value can be expressed as:

$$
\dot{E}_{x}=\dot{E}_{p h}+\dot{E}_{k e}+\dot{E}_{p e}+\dot{E}_{c h}
$$

However, kinetic $\left(\dot{E}_{k e}\right)$ and potential $\left(\dot{E}_{p e}\right)$ exergies are omitted in the present study because they are considered to have insignificant effect.

The physical exergy refers to mechanical and thermal energy which is a function of pressure and temperature differences. The physical exergy, defined by the following expression, cannot be entirely converted to useful work due to entropy generation.

$$
\dot{E}_{p h}=\dot{m}\left[\left(h_{s}-h_{o}\right)-T_{o}\left(s_{s}-s_{o}\right)\right]
$$

Where subscripts $s$ and o represent specified stream and reference states respectively. Once the temperature of specified stream is equal to the reference state value $T S=T o$ for gases and, based on the ideal gas relation, equation (3) becomes:

$$
\dot{E}_{p h}=\dot{m}_{e} R T_{o} \ln \frac{P_{e}}{P_{o}}
$$

The chemical exergy is defined as a maximum energy can be obtained when the system moves forward from the environmental state to the dead state. In the former condition the system is in thermal and mechanical equilibrium whereas the latter state is also in 
chemical equilibrium. Chemical exergy is important during the process of combustion, or mixing, or any case where the composition of the flow stream changes due to substance exchange and heat transfer only. Chemical exergy is subjected to degradation and for a gas mixture can be calculated by:

$$
\dot{E}_{c h}=\dot{n}\left[\sum y_{k} \bar{e}_{k}^{c h}+\bar{R} T_{o} \sum y_{k} \ln y_{k}\right]
$$

Where $\mathrm{y}$ and $\bar{e}_{k}^{c h}$ are molar fraction and molar chemical exergy for component $\mathrm{k}$ in the mixture. Standard chemical exergies tables shows different molar values for chemical exergy based on the substance [12].

The exergy balance equation shows energy degradation due to irreversibilities in the process. For steady-state processes, the balance equation can be expressed as:

$$
\dot{E}_{d}=\sum \dot{E}_{i}-\sum \dot{E}_{e}
$$

Where $\dot{E}_{d}$ is the exergy destruction of each component in the process due to entropy generation. The exergetic efficiency measures the performance of the thermal plant system from a thermodynamic prospective. The exergetic efficiency is defined as the ratio of total exergy output to total exergy input or the ratio of produced exergy to fuel exergy supplied to the system, i.e.

$$
\eta_{e x}=\frac{\dot{E}_{p}}{\dot{E}_{f}}=1-\frac{\dot{E}_{d}+\dot{E}_{l}}{\dot{E}_{f}}
$$

Where $\dot{E}_{d}$ and $\dot{E}_{l}$ represent rates of exergy destruction and exergy loss.

\subsection{Exergoeconomic Analysis}

Exergoeconomic methodology is used to calculate the costs of product, fluid streams and exergy destroyed within the cycle components. The aim of this approach is to minimize the exergy cost and so enhance cost effectiveness of the entire system. It can be treated as tool to minimization exergy costs. The exergoeconomic analysis combined second law thermodynamic evaluations and economic principles. 


\subsubsection{Economic analysis}

The economic analysis includes all necessary financial information needed to evaluate the cost-effectiveness of the energy system. The levelised capital cost of equipment and operation and maintenance (O\&M) costs of each component in the gas turbine engine is needed as well as the levelised cost of fuel (see Section 3.3.1.2).

\subsubsection{Exergy Costing}

Exergy costing refers to the cost of a number of streams entering or exiting a system that is operating at steady-state, and to both work and heat interactions with the surroundings in terms of exergy rates. The cost of exergy destructions caused by irreversibilities within a system can be calculated from the difference between the exergy transfers into and out of the system. The associated costs of the stream entering, the stream exiting, work and heat can be written, respectively, as: -

$$
\begin{gathered}
\dot{C}_{i}=c_{i} \dot{E}_{i} \\
\dot{C}_{e}=c_{e} \dot{E}_{e} \\
\dot{C}_{w}=c_{w} \dot{E}_{w} \\
\dot{C}_{q}=c_{q} \dot{E}_{q}
\end{gathered}
$$

Where $c_{i}, c_{e}, c_{w}$ and $c_{q}$ represent average costs per unit of exergy in dollars per gigajoule $(\$ / G J)$. It is usual for exergy costing to be formulated separately for each component in the system. To balance the cost for the kth component of a system, the sum of the cost rates associated with each exergy stream entering, plus capitalinvestment cost $\left(\dot{Z}_{k}^{C I}\right)$ and the cost of operation and maintenance $\left(\dot{Z}_{k}^{O M}\right)$ equals the sum of the cost rates associated with exiting exergy streams. A general balance equation for the $\mathrm{k}^{\text {th }}$ component receiving a heat input, and generating power takes the form:

$$
\dot{C}_{q, k}+\sum_{i} \dot{C}_{i, k}+\dot{Z}_{k}^{T}=\dot{C}_{w, k}+\sum_{e} \dot{C}_{e, k}
$$

Substituting equations (9-12) in equation (14), the cost balance formulation becomes:

$$
c_{q, k} \dot{E}_{q, k}+\sum_{i} c_{i, k} \dot{E}_{i, k}+\dot{Z}_{k}^{T}=c_{w, k} \dot{E}_{w, k}+\sum_{e} c_{e, k} \dot{E}_{e, k}
$$

Appling the cost balance equation to all system components leads to a number of 
unknown variables larger than the number equation, and hence auxiliary equations are required to achieve a solution. This will give a linear system of equations which, in matrix notation, appears as:

$$
\left[\dot{E}_{k}\right] X\left[c_{k}\right]=\left[\dot{Z}_{k}\right]
$$

Where $\left[\dot{E}_{k}\right]$ is an exergy-rate matrix obtained from exergy analysis, $\left[\dot{Z}_{k}\right]$ is the vector of total cost, which is obtained from economic analysis, and $\left[c_{k}\right]$ is a vector representing the exergetic cost. The cost balance equations for all components in an intercooled gas turbine (ICGT) engine is discussed in more detail in Appendix-A.

\subsubsection{Levelisation}

During a plant's life, there is a non-uniform escalation in operation, maintenance and fuel costs. The cost varies year by year, but the expenditure in any one year equals, on average, the previous years' costs multiplied by the nominal escalation rate $\left(1+r_{n}\right)$. The present worth (PW) constitutes an equivalent value at some given year in the future. The salvage value $\left(S_{v}\right)$ is the estimated value to be collect upon the sale of plant at the end of its useful life[12][13].

$$
\begin{aligned}
& P W=C I C-S_{v} . P W F \\
& S_{v}=j . C I C
\end{aligned}
$$

Where CIC, j, $S_{v}$ and PWF are capital cost, salvage rate (\%), salvage value and present worth factor respectively. PWF is used to simplify the PW calculation and is written as:

$$
P W F=\frac{1}{\left(1+i_{e f f}\right)^{n}}
$$

Where $\mathrm{i}_{\text {eff }}$ represents the discount rate and $\mathrm{n}$ the relevant number of years. The capital recovery factor (CRF) converts a present value to a series of uniform payments over a specified time, at a specified discount rate, so as to recover an initial investment.

$$
C R F=\frac{i_{e f f}\left(1+i_{e f f}^{n}\right)}{\left(1+i_{e f f}\right)^{n}+1}
$$

The annual capital cost (ACIC) is given by: 


$$
A C I C=C R F . P W F(i, n)
$$

The hourly levelised cost of plant and $\mathrm{k}^{\text {th }}$ component are given by:

$$
\begin{aligned}
\dot{Z}^{T} & =\frac{A C I C}{\tau} \\
\dot{Z}_{k} & =\dot{Z}^{T} \frac{E P C_{k}}{\sum E P C_{k}}
\end{aligned}
$$

Where $\tau$ represent number of operational hours per year. The exergoeconomic parameters were introduced in equations (16-22) for current models, and are shown in Table .

Table 2: Exergoeconomic Parameters for current study.

\begin{tabular}{lll}
\hline Parameter & Unit & Value \\
\hline Annual operation hours $(\tau \mathrm{\tau})$ & $\mathrm{h} /$ year & 8,000 \\
\hline Engine life time $(\mathrm{n})$ & year & 20 \\
\hline Nominal escalation rate $\left(\mathrm{r}_{\mathrm{n}}\right)$ & $\%$ & 5.0 \\
\hline Discount rate $\left(\mathbf{i}_{\text {eff }}\right)$ & $\%$ & 6.0 \\
\hline Fuel price $(\mathrm{FP})$ & $\$ / \mathrm{GJ}$ & 5.0 \\
\hline Lower heating value $(\mathrm{LHV})$ & $\mathrm{kJ} / \mathrm{kg}$ & 46,800
\end{tabular}

\subsubsection{The Exergoeconomic Parameters}

The relative cost difference $r_{k}$ and exergoeconomic factor $f_{k}$ are important exergoeconomic variables used to evaluate and optimize thermal systems. relative cost difference represents the relative increase in average cost per exergy unit between fuel and product. Minimizing relative cost difference is an objective function in the optimization process and can be expressed for the $\mathrm{k}^{\text {th }}$ component by:

$$
r_{k}=\frac{c_{p, k}-c_{f, k}}{c_{f, k}}=\frac{1-\eta_{e x, k}}{\eta_{e x, k}}+\frac{\dot{z}_{k}^{C I}+\dot{z}_{k}^{O M}}{c_{f, k} \dot{E}_{p, K}}
$$

Where subscripts $p$ and $f$ represent product and fuel, respectively. The cost of the $\mathrm{k}^{\text {th }}$ 
component can be attributed to two sources. The first is related to exergy destruction and exergy loss, whereas the second is related to non-exergy quantities, such as capital investment or operation and maintenance costs. It is useful during the evaluation process to know the relative significance of each source. The exergoeconomic factor can provide this information and determine the relative weight of each source. The exergoeconomic factor $f_{k}$ can be formulated as:

$$
f_{k}=\frac{\dot{Z}_{k}}{\dot{Z}_{k}+c_{f, k}\left[\dot{E}_{d, k+} \dot{E}_{L, k}\right]}
$$

\subsection{Exergoenvironmental Analysis}

Exergoenvironmental analysis is a powerful tool that combines the concepts of exergy and environmental damage. The exergy analysis has a significant relationship with environmental impact, because it is based on three factors that strongly affect sustainability; order of destruction, waste exergy emission, and resource degradation. Carbon dioxide $\left(\mathrm{CO}_{2}\right)$ emission is considered in the current work because it can be related to energy system efficiency and represents about $50 \%$ of the greenhouse effect. The amount of $\mathrm{CO}_{2}(\mathrm{~kg} / \mathrm{kWh})$ emission is evaluated using a generic combustor model. The total cost of $\mathrm{CO}_{2}$ can be calculated by multiplying its flow rates by $0.024 \$ / \mathrm{kg}$ and then adding this sum directly to the fuel cost [14], [16].

\section{Results and discussion}

In this section, results of exergy, exergoeconomic and exergoenvironmental analysis are presented for an advanced aero-derivative ICGT and a SCGT. Exergy analysis assists in quantifying the inefficiencies and identifying source of losses in an energy system, allowing the energy conversion of the system to be enhanced with respect to both product cost and environmental impact. The ambient environmental state was selected as pressure of 1.013 bar and temperature of $288.0 \mathrm{~K}$ (ISO conditions).

Table-2 shows the exergetic data of ICGT at ISO ambient conditions. Similar analyses were performed for different load condition at ambient temperatures of $308.0 \mathrm{~K}$ and 323.0 K, see Appendix B. 
Table 2. Exergetic data for ICGT gas turbine engine.

\begin{tabular}{|c|c|c|c|c|c|c|c|}
\hline State & Substance & $\begin{array}{c}\text { Mass } \\
\text { flow } \\
{[\mathrm{Kg} / \mathbf{s}]}\end{array}$ & $\begin{array}{l}\text { Temp. } \\
\text { [K] }\end{array}$ & $\begin{array}{l}\text { Pressure } \\
\text { [bar] }\end{array}$ & $\begin{array}{c}\text { Exergy } \\
\dot{\boldsymbol{E}}_{\boldsymbol{p h}} \\
{[\mathrm{MW}]}\end{array}$ & $\begin{array}{c}\text { Exergy } \\
\dot{E}_{c h} \\
{[\mathbf{M W}]}\end{array}$ & $\begin{array}{c}\text { Exergy } \\
\dot{\boldsymbol{E}}_{\boldsymbol{x}} \\
{[\mathbf{M W}]}\end{array}$ \\
\hline 1 & Air & 217.1 & 288.0 & 1.013 & 0.000 & 0.290 & 0.290 \\
\hline 2 & Air & 217.1 & 420.8 & 3.44 & 27.24 & 0.290 & 27.53 \\
\hline 2 & Air & 217.1 & 325.4 & 3.28 & 21.66 & 0.290 & 21.95 \\
\hline 3 & Air & 217.1 & 701.6 & 42.0 & 102.8 & 0.290 & 103.1 \\
\hline 4 & Fuel & 4.930 & 288.0 & 45.0 & 2.670 & 220.0 & 222.9 \\
\hline 5 & $\begin{array}{l}\text { Exhaust } \\
\text { gases }\end{array}$ & 222.0 & 1490 & 39.8 & 262.7 & 1.850 & 264.5 \\
\hline 6 & \multicolumn{4}{|c|}{ Power to HPC } & 87.91 & ---- & 87.91 \\
\hline 7 & $\begin{array}{l}\text { Exhaust } \\
\text { gases }\end{array}$ & 222.0 & 1182 & 12.7 & 173.2 & 1.850 & 175.0 \\
\hline 8 & \multicolumn{4}{|c|}{ Power to LPC } & 29.57 & ---- & 29.57 \\
\hline 9 & $\begin{array}{l}\text { Exhaust } \\
\text { gases }\end{array}$ & 222.0 & 1074 & 8.02 & 142.4 & 1.850 & 144.3 \\
\hline 10 & \multicolumn{4}{|c|}{ Net Power } & 98.75 & ---- & 98.75 \\
\hline 11 & $\begin{array}{l}\text { Exhaust } \\
\text { gases }\end{array}$ & 222.0 & 685.0 & 1.013 & 35.74 & 1.850 & 37.59 \\
\hline
\end{tabular}

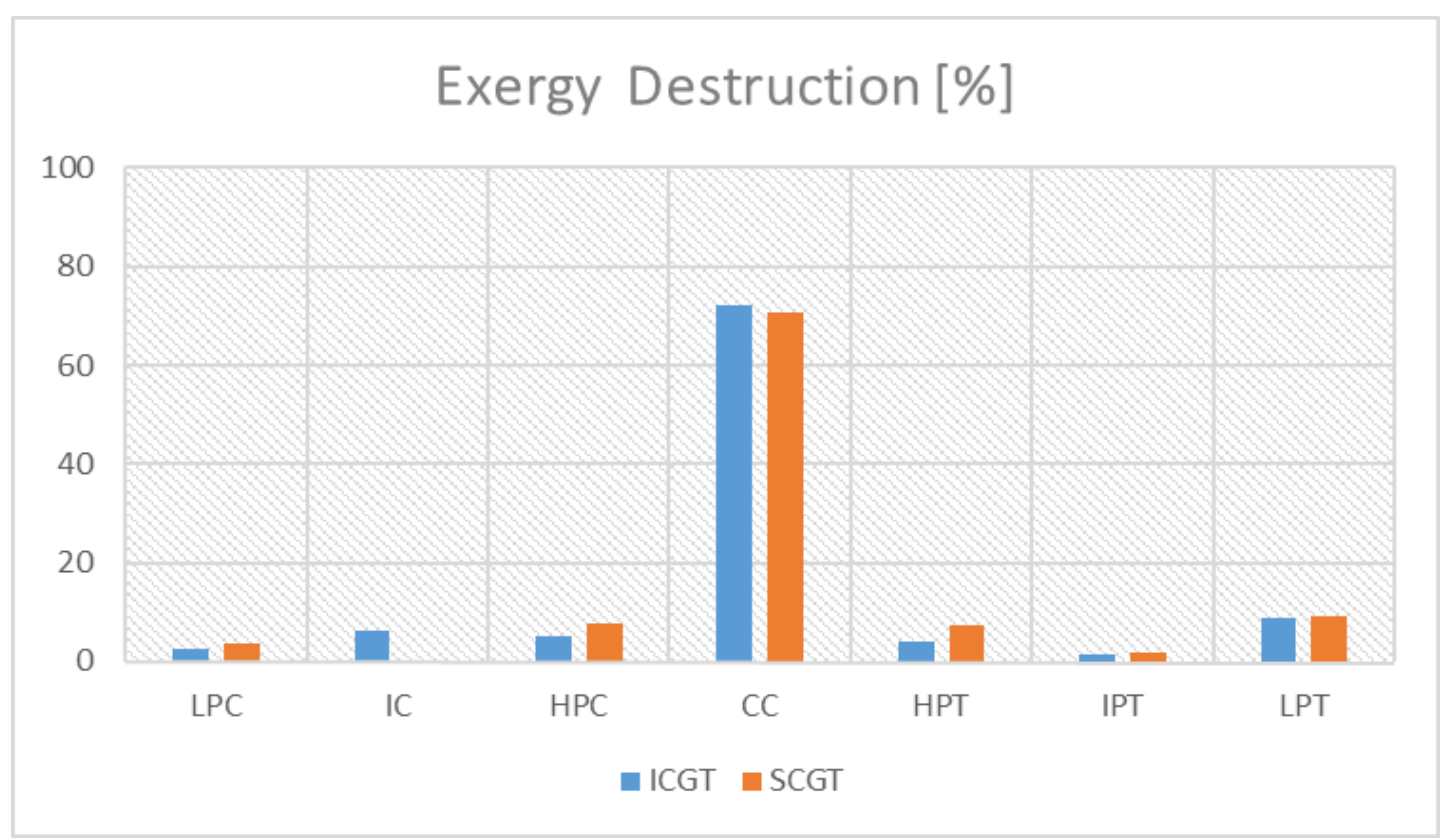

Figure 2. Exergy destruction for ICGT and SCGT at ISO ambient conditions.

Figure 2 presents the exergy destruction rates for both ICGT and SCGT under the given ambient conditions. The highest exergy destruction for both systems occurs in the combustion chamber $(\mathrm{CC})$ due to chemical reactions, mixing and sharp temperature 
differences. The exergy destruction rate in the CC is higher for the ICGT than the SCGT, due to the lower temperature of the compressed air resulting in greater consumption of fuel. The high pressure components, HPC and HPT, of the SCGT have higher exergy destruction rates than the ICGT due to intercooling effects that reduce both (eat losses and power consumption. The LPT has high irreversibilities against all rotating component due to high blade size and power output. The ICGT deliver more useful work than the SCGT because of energy savings in the high pressure compressor.

The effect of ambient temperature on the exergetic efficiency and net power output of the proposed systems is shown in Figure-3. The exergetic efficiency and net power output decreased as the ambient temperature increased due to increased power consumption by the low pressure compressor as a result of decreased air density.

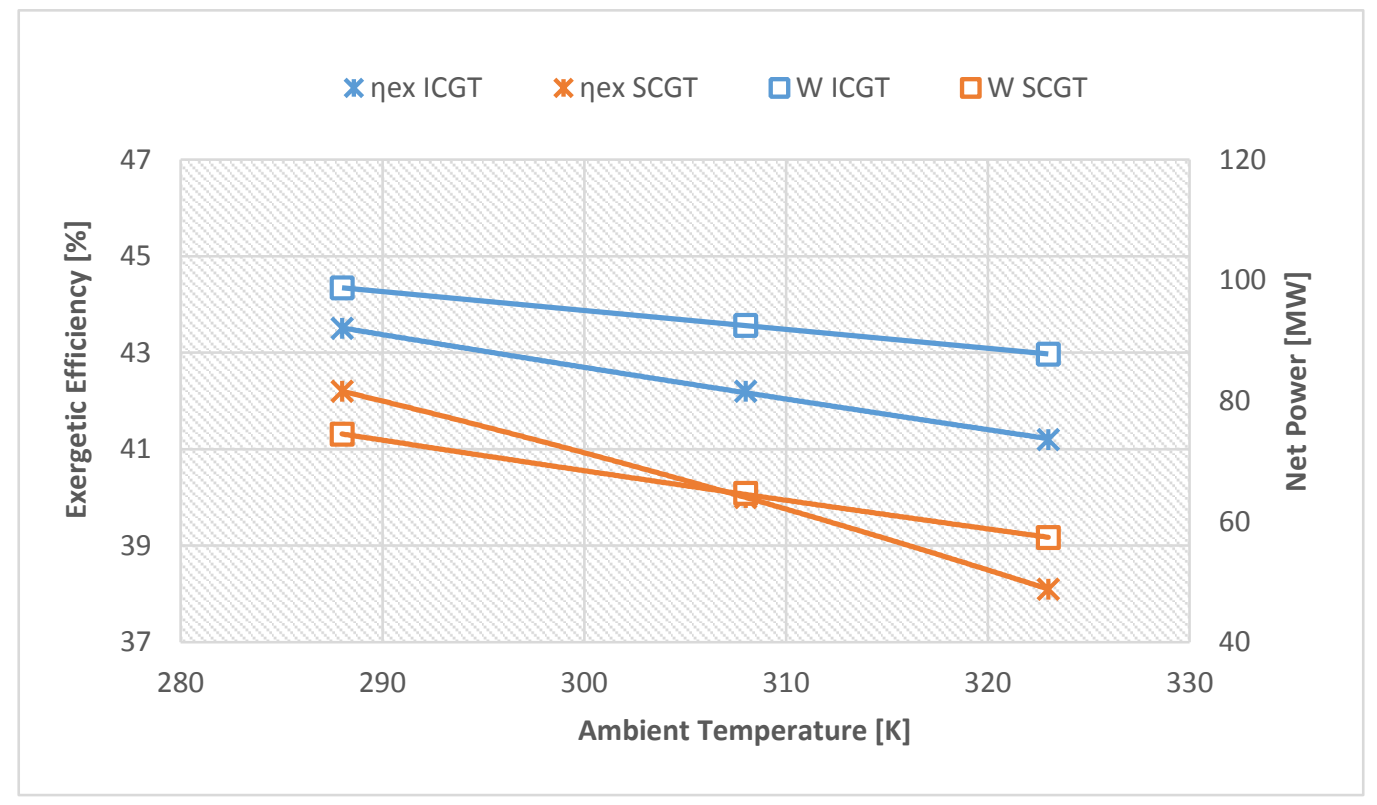

Figure 3. Exergetic efficiency and net power output versus ambient temperature.

From an operational perspective, a full load is preferable because the gas turbine operates at optimum efficiency, but the rate of decrease of exergetic efficiency for the ICGT system is less than for the SCGT owing to intercooling which minimizes the effect of ambient temperature variation on the HPC. The exergetic efficiency and net power output for the ICGT has a higher value than for the SCGT because of the saving of electrical energy in HPC is more than the fuel consumed in the combustor. Furthermore, the quality of electrical energy is higher than that of chemical energy since there is no entropy generation and it can be converted entirely to useful work. Ambient temperature 
variation can be largely eliminated by cooling the inlet air stream at the intake of the gas turbine using a cooling system such as absorption chiller.

Operational flexibility is one of the main advantages of a gas turbine compared to other energy systems, but load variation has a substantial effect on gas turbine performance. The electrical grid network is subject to substantial load variation based on end user demand. ICGTs perform well at full load and part loads above 90\%. However, SCGTs show a slightly higher efficiency from about $90 \%$ down to minimum safe load, as illustrated in Figure-4. The amount of fuel consumed and turbine inlet temperature (TIT) reduce with load as compatible with turbine requirements. The main reason behind the performance superiority of SCGT at these lower (part) loads is the reduction in electrical energy consumed by the compressor compared with the reduction in fuel consumed.

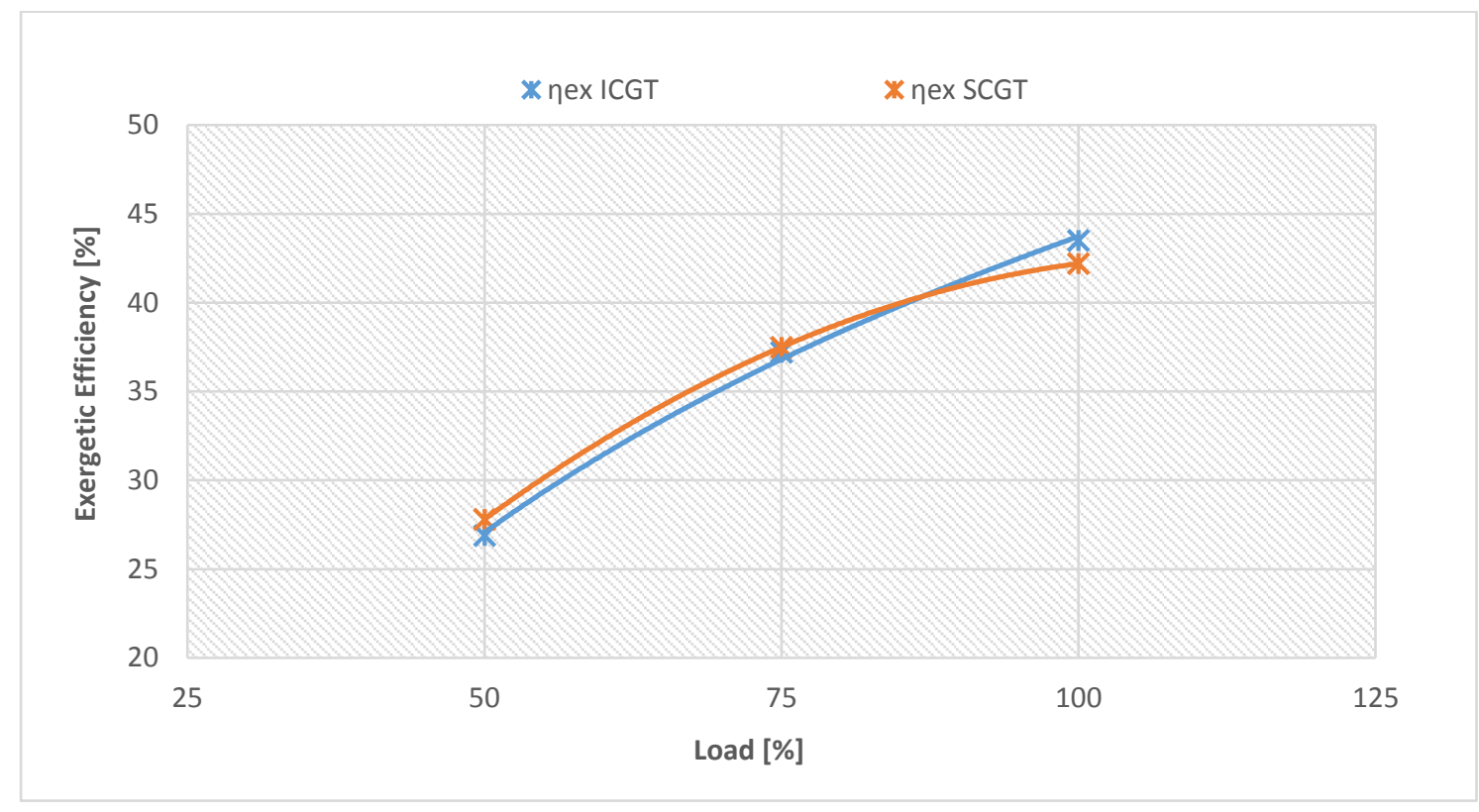

Figure 4. Exergetic efficiency versus load variation at ISO condition.

The sum of exergy destruction and component costs for the ICGT and SCGT are shown in Figure 5. From an exergoeconomic viewpoint the highest values of $\dot{C}_{d}+\dot{Z}_{k}^{T}$ indicate the most important components in the system to adjust to enhance the cost effectiveness of the entire system. 


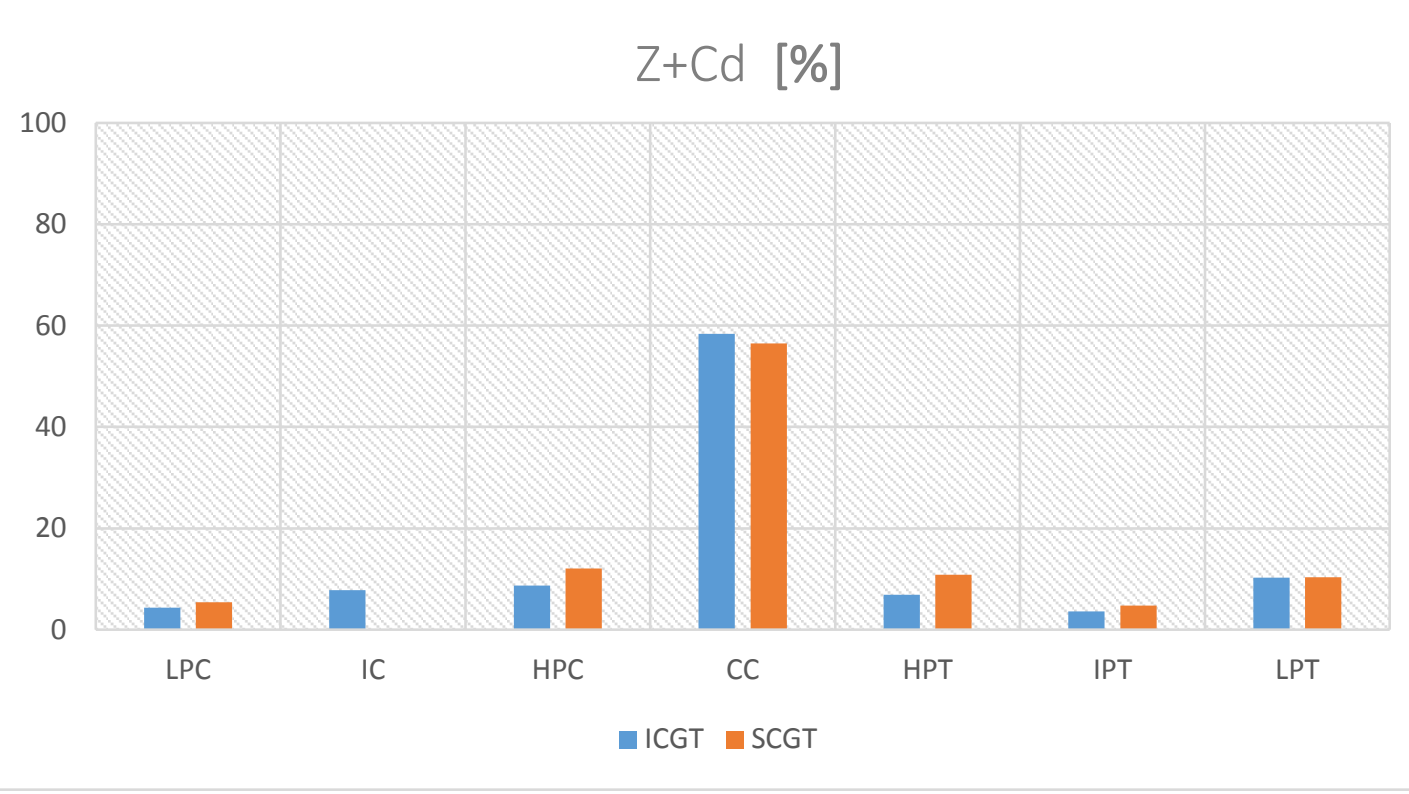

Figure 5. The relative percentages of exergy destruction and component costs for all components in the proposed gas turbine engine systems.

Obviously, by far the most important element for exergy destruction and component costs is the combustion chamber. This is followed by the HPC, the high pressure turbine (HPT) and the LPT, though the relative order of these elements depends on whether the ICGT or the SCGT is being considered. The impact of improving component performance on reducing product cost, e.g. enhancing system cost effectiveness, can be determined based on the exergoeconomic factors, as shown in Figure-6. The combustion chamber has a low exergoeconomic factor due to its high rate of exergy destruction compared to the other elements, see Figure 5. That mean more modifications are required in expense of capital cost because the exergy destruction contribute more in total cost. Exergy destruction in the combustion chamber can be reduced slightly by preheating the reactants, decreasing heat loss, and adjusting the amount of excess air. Using waste heat in the exhaust gases to preheat the reactants provides the dual benefit of reducing exergy loss and improving combustion chamber performance by decreasing fuel combustion. The overall exergetic efficiency will increase accordingly. In the high pressure components and PT, improvements in efficiency will require increased capital expenditure and maintenance costs. The intermediate pressure turbine has the highest exergoeconomic factor, this indicates that investment and O\&M costs are slightly higher than the costs associated with exergy destruction. Therefore, reducing $\dot{Z}_{k}^{T}$ by decreasing the values of inlet temperature, expansion ratio, or component efficiency is required. However, the HPC in the ICGT has a lower value of $\dot{C}_{d}+\dot{Z}_{k}^{T}$ compared with the SCGT due to the intercooler, which reduces inlet temperature, thereby reducing power consumption and increasing net power output. 


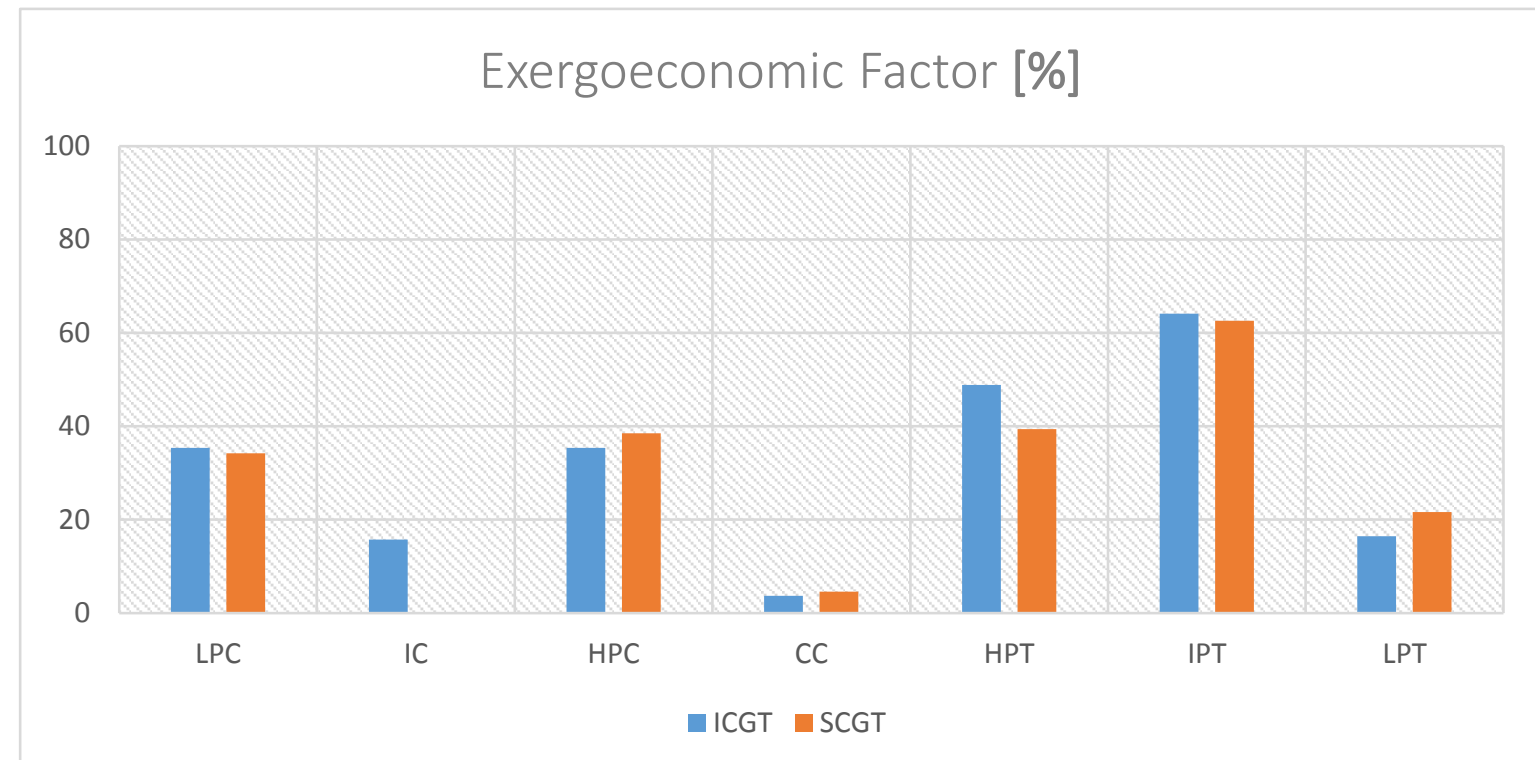

Figure 6. Exergoeconomic factors for engine components for both ICGT and SCGT.

The power output costs of ICGT and SCGT are 8.32 and 8.59 \$/GJ respectively at design condition. Thus, from an economic perspective the ICGT performs better than the SCGT. However, maximum carbon dioxide $\mathrm{CO}_{2}$ emission occurs at stoichiometric air to fuel ratio, which suggests that a large amount of $\mathrm{CO}_{2}$ will be emitted when the engine operates at or near its maximum efficiency. The lowest value of $\mathrm{kgCO}_{2} / \mathrm{kWh}$ is the major objective when reducing environmental impact. Figure-7 shows the amounts of $\mathrm{kgCO}_{2} / \mathrm{kWh}$ emitted at different ambient temperatures for both ICGT and SCGT. The $\mathrm{CO}_{2}$ emission per $\mathrm{kWh}$ increases proportionally with increase in ambient temperature. The SCGT produces higher levels of $\mathrm{CO}_{2}$ emission than the ICGT due to more power generated per kg of fuel. Consequently, the ICGT has a lower environmental impact and is considered the better choice.

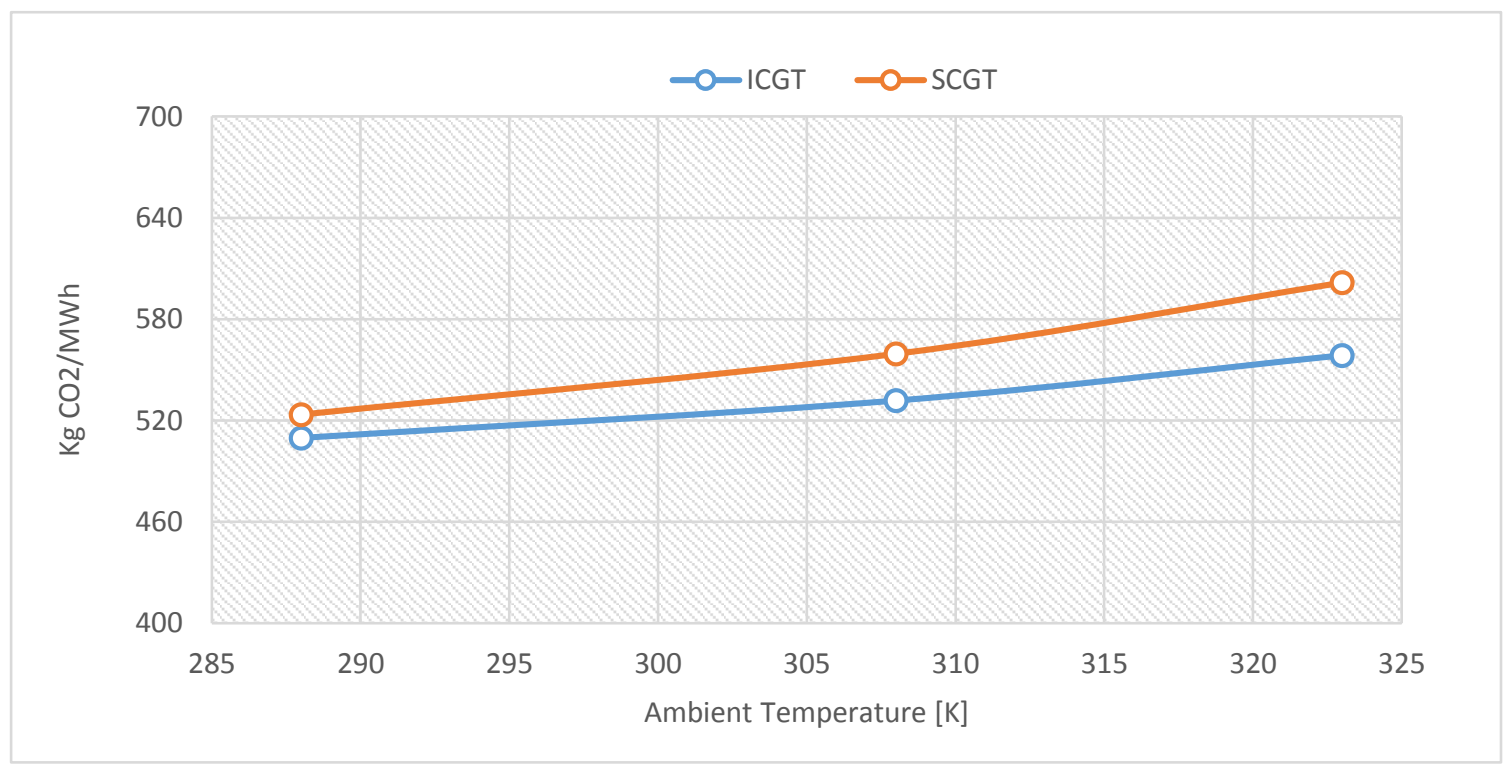

Figure 7. CO2 emissions for ICGT and SCGT per kWh of electrical energy generated. 


\section{Conclusion}

This paper presented exergetic, exergoeconomic and exergoenvironmental analyses of an advanced aero-derivative intercooled gas turbine engine modelled using the IPSEpro software package and validated using manufacturer's data, with good agreement. The major sources of irreversibilities are in the combustion chamber with exergy destructions of $72.0 \%$ and $70.6 \%$ for ICGT and SCGT respectively. The intercooled system has negative impact on combustion chamber performance in spite of improving the overall efficiency. The exergetic efficiency and net power output are inversely proportional to the ambient temperature. Operationally, the part load condition is not preferable due to high reduction in net power output compared to the amount of fuel saved. The exergoeconomic assessment has introduced useful information by evaluating the components individually to enhance the cost effectiveness of the entire system. The product cost of ICGT is equal to $8.32 \$ / G J$ while for the SCGT is $8.59 \$ / G J$. Furthermore, in terms of $\mathrm{CO}_{2}$ production, the ICGT is more environmentally friendly than the SCGT. 


\section{Nomenclature}

$\dot{C}$

c

$\dot{\mathrm{E}}$

$\bar{e}_{\mathrm{k}}^{\mathrm{ch}}$

$f_{k}$

$\mathrm{h}$

$\overline{\mathrm{h}}$

$i_{\text {eff }}$

j

$\overline{\mathrm{LHV}}$

$\mathrm{M}$

$\dot{\mathrm{m}}$

n

$\mathrm{P}$

$\dot{Q}$

$\mathrm{R}$

$\overline{\mathrm{R}}$

$r_{k}$

$r_{n}$

$\mathrm{S}$

$\overline{\mathrm{s}}$

$\dot{S}_{\text {gen }}$

$\mathrm{T}$

V

W

$\dot{Z}$

Greek symbols
$\eta_{e x}$
Exergetic efficiency
$\mu_{\mathrm{k}}$
chemical potential

Cost rate

Average unit cost

Exergy rate

Molar chemical exergy

Exergoeconomic factor

Enthalpy

Molar enthalpy

Discount rate

Salvage rate

Low heating value in molar basis

Molecular weight

Mass flow rate

Number of mole

Pressure

Heat transfer rate

Gas constant

Universal gas constant

Relative cost difference

Nominal escalation rate

Entropy

Molar entropy

Entropy generation

Temperature

Velocity

Work rate

Purchase cost rate 


\section{Subscripts}

$\begin{array}{ll}\text { a } & \text { Air } \\ \text { CI } & \text { Capital investment } \\ \text { ch } & \text { Chemical } \\ \text { d } & \text { destruction } \\ \text { e } & \text { Exit } \\ \text { F } & \text { Fuel } \\ \text { g } & \text { Gravitational acceleration } \\ \text { i } & \text { Inlet } \\ \text { k } & \text { Component } \\ \text { ke } & \text { Kinetic energy } \\ \text { L } & \text { Loss } \\ \text { o } & \text { Reference state } \\ \text { p } & \text { Product } \\ \text { ph } & \text { Physical } \\ \text { pe } & \text { Potentials } \\ \text { S } & \text { Reference state } \\ \text { t } & \text { Turbine } \\ \text { T } & \text { Total } \\ x & \text { Total }\end{array}$

Abbreviations

ACIC

Annual capital cost

$\mathrm{CC}$

Combustion chamber

CIC

Capital cost

CRF

Capital recovery factor

FP

Fuel price

GT

Gas turbine

HPC

High pressure compressor

HPT

High pressure turbine

ICGT

Intercooled cycle gas turbine

IPT

Intermediate pressure turbine

LHV

Lower heating value 


$\begin{array}{ll}\text { LPC } & \text { Low pressure compressor } \\ \text { LPT } & \text { Low pressure turbine } \\ \text { ISO } & \text { International Standards Organization } \\ \text { O\&M } & \text { Operation and maintenance } \\ \text { PEC } & \text { Purchased equipment cost } \\ \text { PRO } & \text { Pressure retarded osmosis } \\ \text { PT } & \text { Power turbine } \\ \text { PW } & \text { Present worth } \\ \text { PWF } & \text { Present worth factor } \\ \text { SCGT } & \text { Simple cycle gas turbine } \\ \text { SPECO } & \text { Specific exergy costing } \\ \text { TIT } & \text { Turbine inlet temperature }\end{array}$




\section{References}

[1] H. William, "PRATT \& WHITNEY'S NEXT GENERATION TURBINE PROGRAM," in DOE Turbine Power Systems Conference and Condition Monitoring Workshop, 2002, pp. 1-12.

[2] P. Jansohn, Modern gas turbine systems: High efficiency, low emission, fuel flexible power generation. Elsevier, 2013.

[3] H. Kwak, D.Kim, and J. Jeon, "Exergetic and thermoeconomic analyses of power plants," Energy, vol. 28, no. 4, pp. 343-360, 2003.

[4] G. Tsatsaronis, "Combination of Exergetic and Economic Analysis in EnergyConversion Processes" Poceedings, European Congress, Energy Economics and Management in Industry, Algarve, Portugal, Pergamon Press, Oxford, England, Vol. 1, pp. 151-157, 1984 .

[5] L. Meyer, R. Castillo, J. Buchgeister, and G. Tsatsaronis, "Application of exergoeconomic and exergoenvironmental analysis to an SOFC system with an allothermal biomass gasifier," Int. J. Thermodyn., vol. 12, no. 4, pp. 177-186, 2009.

[6] G. Tsatsaronis and M. Winhold, "Exergoeconomic analysis and evaluation of energyconversion plants-I. A new general methodology," Energy, vol. 10, no. 1, pp. 69-80, Jan. 1985.

[7] L. G. Alves and S. A. Nebra, "Exergoeconomic study of hydrogen production from steam reforming of natural gas," in ECOS 2005 - Proceedings of the 18th International Conference on Efficiency, Cost, Optimization, Simulation, and Environmental Impact of Energy Systems, 2005, pp. 1123-1130.

[8] S. E. Yalçin and T. Derbentl, "Exergoeconomic analysis of boilers," in ECOS 2006 Proceedings of the 19th International Conference on Efficiency, Cost, Optimization, Simulation and Environmental Impact of Energy Systems, 2006, pp. 459-463.

[9] L. Wang, Y. Yang, C. Dong, Z. Yang, G. Xu, and L. Wu, "Exergoeconomic Evaluation of a Modern Ultra-Supercritical Power Plant," Energies, vol. 5, no. 12, pp. 3381-3397, 2012.

[10] M. Ameri, P. Ahmadi, and A. Hamidi, "Energy, exergy and exergoeconomic analysis of a steam power plant: A case study," Int. J. Energy Res., vol. 33, no. 5, pp. 499-512, Apr. 2009.

[11] Y.-H. Kwon, H.-Y. Kwak, and S.-D. Oh, "Exergoeconomic analysis of gas turbine 
cogeneration systems," Exergy, An Int. J., vol. 1, no. 1, pp. 31-40, 2001.

[12] and M. J. M. Bejan, Adrian, Thermal design and optimization. John Wiley \& Sons, 1996.

[13] O. Turan and H. Aydin, "Exergetic and exergo-economic analyses of an aero-derivative gas turbine engine," Energy, vol. 74, pp. 638-650, 2014.

[14] P. Ahmadi, I. Dincer, and M. a. Rosen, "Exergy, exergoeconomic and environmental analyses and evolutionary algorithm based multi-objective optimization of combined cycle power plants," Energy, vol. 36, no. 10, pp. 5886-5898, 2011.

[15] F. Petrakopoulou, A. Boyano, M. Cabrera, and G. Tsatsaronis, "Exergoeconomic and exergoenvironmental analyses of a combined cycle power plant with chemical looping technology,” Int. J. Greenh. Gas Control, vol. 5, no. 3, pp. 475-482, 2011.

[16] M. a. Ehyaei, a. Mozafari, and M. H. Alibiglou, "Exergy, economic \& environmental (3E) analysis of inlet fogging for gas turbine power plant," Energy, vol. 36, no. 12, pp. 6851-6861, 2011. 


\section{Appendix A - Exergoeconomic Balance Equations}

The following equations were extracted from cost balances and auxiliary relations for each component in the ICGT system.

Low Pressure Compressor [LPC]

$$
\begin{aligned}
\dot{C}_{1}+\dot{C}_{8}+\dot{Z}_{L P C}=\dot{C}_{2} \\
\dot{C}_{1}=0 \quad \text { [Assumption at reference state] }
\end{aligned}
$$

Intercooler $[\mathrm{IC}]$

$$
\begin{gathered}
\dot{C}_{2}+\dot{C}_{A}+\dot{Z}_{I C}=\dot{C}_{2 \prime}+\dot{C}_{B} \\
\frac{\dot{C}_{2}}{\dot{E}_{2}}=\frac{\dot{C}_{2 \prime}}{\dot{E}_{2 \prime}} \quad[\text { F rule }] \\
\dot{C}_{B}=0 \quad \text { [Assumption] }
\end{gathered}
$$

High Pressure Compressor [HPC]

$$
\dot{C}_{2},+\dot{C}_{6}+\dot{Z}_{H P C}=\dot{C}_{3}
$$

Combustion Chamber [CC]

$$
\begin{aligned}
& \dot{C}_{3}+\dot{C}_{4}+\dot{Z}_{C C}=\dot{C}_{5} \\
& \dot{C}_{4}=\text { Fuel price }=\text { Constant }
\end{aligned}
$$

High Pressure Turbine [HPT]

$$
\begin{aligned}
& \dot{C}_{5}+\dot{Z}_{H P T}=\dot{C}_{6}+\dot{C}_{7} \\
& \frac{\dot{C}_{5}}{\dot{E}_{5}}=\frac{\dot{C}_{7}}{\dot{E}_{7}} \quad[\text { F rule }]
\end{aligned}
$$

Intermediate Pressure Turbine [IPT]

$$
\begin{aligned}
& \dot{C}_{7}+\dot{Z}_{I P T}=\dot{C}_{8}+\dot{C}_{9} \\
& \frac{\dot{C}_{7}}{\dot{E}_{7}}=\frac{\dot{C}_{9}}{\dot{E}_{9}} \quad[\text { F rule }]
\end{aligned}
$$


Low Pressure Turbine [LPT]

$$
\begin{aligned}
& \dot{C}_{9}+\dot{Z}_{L P T}=\dot{C}_{10}+\dot{C}_{11} \\
& \frac{\dot{C}_{9}}{\dot{E}_{9}}=\frac{\dot{C}_{11}}{\dot{E}_{11}} \quad[\text { F rule }]
\end{aligned}
$$

Fuel cost in $\$ / \mathrm{h}$ can be calculated using the following equation.

$$
\text { Fuel price }=3600 . \tau . \text { FP. LHV. } \dot{m}_{f}
$$

$$
\text { Fuel price }=3600\left[\frac{S}{h}\right] * 8000\left[\frac{h}{y}\right] * 0.005\left[\frac{\$}{M J}\right] * 46.802\left[\frac{M J}{K g}\right] * 4.93\left[\frac{\mathrm{kg}}{\mathrm{s}}\right]
$$

Fuel price $=33.22 \times 10^{6} \$ /$ year $=3793 \$ / \mathrm{h}$

The variable of cost per exergy unit $\left(\dot{C}_{1}-\dot{C}_{11}\right)$ is solved by using the system of linear equations (A-1) to (A-14) as follows:

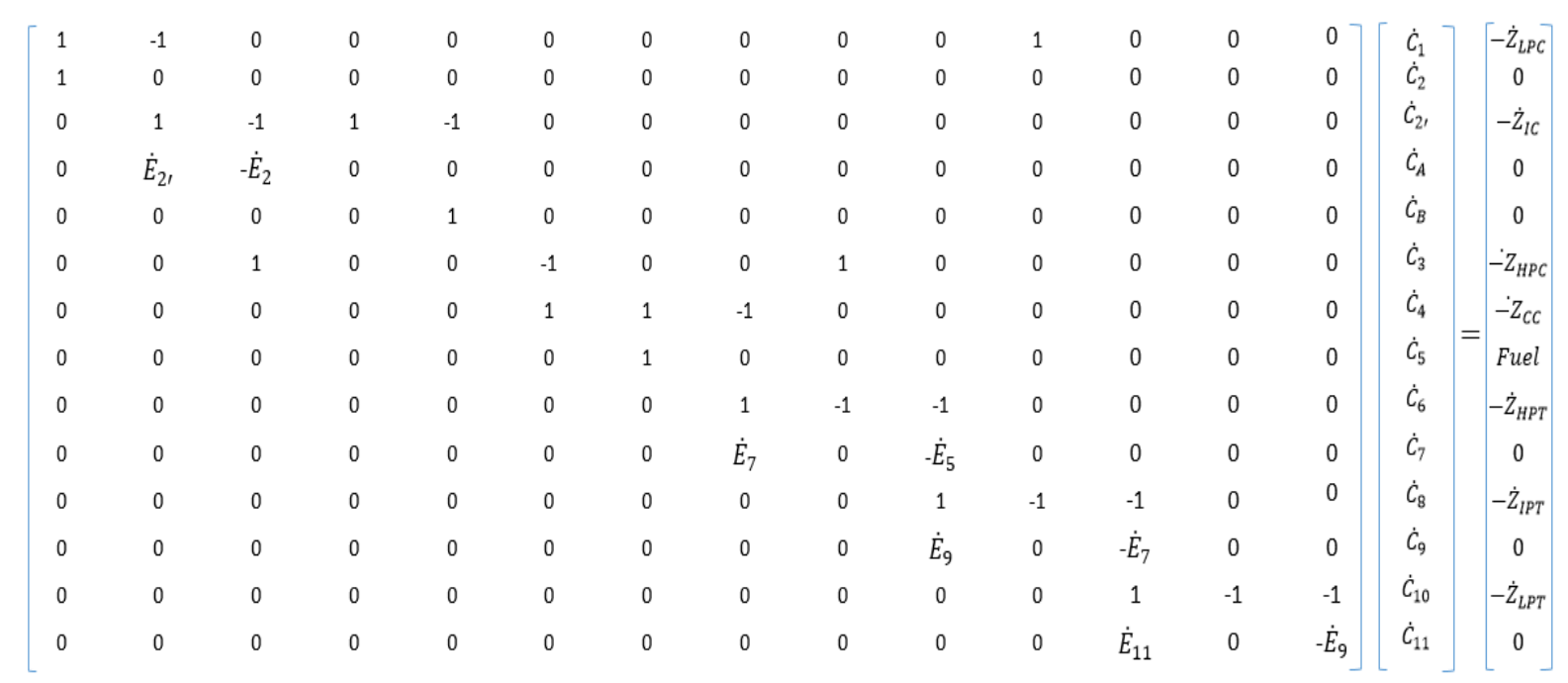


Appendix B - Sample of Design and Off Design Results

Table. B-1 Exergetic data for SCGT gas turbine engine at ISO condition.

\begin{tabular}{|c|c|c|c|c|c|c|c|}
\hline State & Substance & $\begin{array}{c}\text { Mass } \\
\text { flow } \\
{[\mathrm{Kg} / \mathrm{s}]}\end{array}$ & $\begin{array}{c}\text { Temp. } \\
{[\mathrm{K}]}\end{array}$ & $\begin{array}{c}\text { Pressure } \\
\text { [bar] }\end{array}$ & $\begin{array}{c}\text { Exergy } \\
\dot{\boldsymbol{E}}_{p h} \\
{[\mathbf{M W}]}\end{array}$ & $\begin{array}{c}\text { Exergy } \\
\dot{E}_{c h} \\
{[\mathrm{MW}]}\end{array}$ & $\begin{array}{c}\text { Exergy } \\
\dot{\boldsymbol{E}}_{\boldsymbol{x}} \\
{[\mathbf{M W}]}\end{array}$ \\
\hline 1 & Air & 217.1 & 288.0 & 1.010 & 0.000 & 0.290 & 0.290 \\
\hline 2 & Air & 217.1 & 420.8 & 3.440 & 27.24 & 0.290 & 27.50 \\
\hline 3 & Air & 217.1 & 889.6 & 44.10 & 132.4 & 0.290 & 133.0 \\
\hline 4 & Fuel & 3.810 & 288.0 & 45.00 & 2.060 & 170.0 & 172.0 \\
\hline 5 & Exhaust gases & 220.9 & 1490 & 41.90 & 259.9 & 1.840 & 262.0 \\
\hline 6 & \multicolumn{4}{|c|}{ Power to HPC } & 110.2 & --- & 110.0 \\
\hline 7 & Exhaust gases & 220.9 & 1086 & 8.860 & 144.8 & 1.840 & 147.0 \\
\hline 8 & \multicolumn{4}{|c|}{ Power to LPC } & 29.57 & ---- & 29.60 \\
\hline 9 & Exhaust gases & 220.9 & 973.6 & 5.350 & 113.9 & 1.840 & 116.0 \\
\hline 10 & \multicolumn{4}{|c|}{ Net Power } & 74.47 & ---- & 74.50 \\
\hline 11 & Exhaust gases & 220.9 & 672.4 & 1.013 & 33.44 & 1.840 & 35.30 \\
\hline
\end{tabular}


Table. B-2 Exergetic data for SCGT gas turbine engine at 75\% part load.

\begin{tabular}{|c|c|c|c|c|c|c|c|}
\hline State & Substance & $\begin{array}{c}\text { Mass } \\
\text { flow } \\
{[\mathrm{Kg} / \mathrm{s}]}\end{array}$ & $\begin{array}{c}\text { Temp. } \\
{[\mathrm{K}]}\end{array}$ & $\begin{array}{c}\text { Pressure } \\
\text { [bar] }\end{array}$ & $\begin{array}{c}\text { Exergy } \\
\dot{\boldsymbol{E}}_{\boldsymbol{p h}} \\
{[\mathrm{MW}]}\end{array}$ & $\begin{array}{c}\text { Exergy } \\
\dot{E}_{c h} \\
{[\mathrm{MW}]}\end{array}$ & $\begin{array}{c}\text { Exergy } \\
\dot{E}_{x} \\
{[\mathrm{MW}]}\end{array}$ \\
\hline 1 & Air & 217.1 & 288.0 & 1.013 & 0.000 & 0.290 & 0.290 \\
\hline 2 & Air & 217.1 & 420.8 & 3.440 & 27.24 & 0.290 & 27.53 \\
\hline 3 & Air & 217.1 & 889.6 & 44.10 & 132.4 & 0.290 & 132.7 \\
\hline 4 & Fuel & 3.190 & 288.0 & 45.00 & 2.060 & 142.5 & 144.6 \\
\hline 5 & Exhaust gases & 220.3 & 1400 & 41.90 & 237.8 & 1.840 & 239.6 \\
\hline 6 & \multicolumn{4}{|c|}{ Power to HPC } & 110.2 & ---- & 110.2 \\
\hline 7 & Exhaust gases & 220.3 & 987.1 & 7.710 & 122.3 & 1.840 & 124.2 \\
\hline 8 & \multicolumn{4}{|c|}{ Power to LPC } & 29.57 & ---- & 29.57 \\
\hline 9 & Exhaust gases & 220.3 & 871.4 & 4.400 & 91.34 & 1.840 & 93.18 \\
\hline 10 & \multicolumn{4}{|c|}{ Net Power } & 55.85 & --- & 55.85 \\
\hline 11 & Exhaust gases & 220.9 & 640.18 & 1.133 & 30.84 & 1.840 & 32.68 \\
\hline
\end{tabular}


Table. B-3 Exergetic data for ICGT gas turbine engine at $308 \mathrm{~K}$ ambient temperature.

\begin{tabular}{|c|c|c|c|c|c|c|c|}
\hline State & Substance & $\begin{array}{c}\text { Mass } \\
\text { flow } \\
{[\mathrm{Kg} / \mathbf{s}]}\end{array}$ & $\begin{array}{c}\text { Temp. } \\
{[\mathrm{K}]}\end{array}$ & $\begin{array}{c}\text { Pressure } \\
\text { [bar] }\end{array}$ & $\begin{array}{c}\text { Exergy } \\
\dot{\boldsymbol{E}}_{p h} \\
{[\mathrm{MW}]}\end{array}$ & $\begin{array}{c}\text { Exergy } \\
\dot{E}_{c h} \\
{[\mathrm{MW}]}\end{array}$ & $\begin{array}{c}\text { Exergy } \\
\dot{\boldsymbol{E}}_{\boldsymbol{x}} \\
{[\mathrm{MW}]}\end{array}$ \\
\hline 1 & Air & 217.1 & 308.0 & 1.013 & 0.000 & 0.290 & 0.290 \\
\hline 2 & Air & 217.1 & 449.7 & 3.44 & 29.26 & 0.290 & 29.55 \\
\hline 2 & Air & 217.1 & 340.9 & 3.28 & 21.98 & 0.290 & 22.27 \\
\hline 3 & Air & 217.1 & 732.9 & 42.0 & 107.1 & 0.290 & 107.4 \\
\hline 4 & Fuel & 4.750 & 288.0 & 45.0 & 2.67 & 212.2 & 214.9 \\
\hline 5 & Exhaust gases & 221.9 & 1490 & 39.82 & 262.0 & 1.850 & 263.9 \\
\hline 6 & \multicolumn{4}{|c|}{ Power to HPC } & 89.96 & ---- & 89.96 \\
\hline 7 & Exhaust gases & 221.9 & 1166 & 11.87 & 168.4 & 1.850 & 170.2 \\
\hline 8 & \multicolumn{4}{|c|}{ Power to LPC } & 31.61 & --- & 31.61 \\
\hline 9 & Exhaust gases & 221.9 & 1050 & 7.22 & 135.4 & 1.850 & 137.3 \\
\hline 10 & \multicolumn{4}{|c|}{ Net Power } & 92.53 & --- & 92.53 \\
\hline 11 & Exhaust gases & 221.9 & 683.8 & 1.013 & 35.48 & 1.850 & 37.33 \\
\hline
\end{tabular}


Table. B-4 Exergetic data for ICGT gas turbine engine at 50\% part load.

\begin{tabular}{|c|c|c|c|c|c|c|c|}
\hline State & Substance & $\begin{array}{c}\text { Mass } \\
\text { flow } \\
{[\mathrm{Kg} / \mathrm{s}]}\end{array}$ & $\begin{array}{l}\text { Temp. } \\
{[\mathrm{K}]}\end{array}$ & $\begin{array}{c}\text { Pressure } \\
\text { [bar] }\end{array}$ & $\begin{array}{c}\text { Exergy } \\
\dot{E}_{p h} \\
{[\mathrm{MW}]}\end{array}$ & $\begin{array}{r}\text { Exergy } \\
\dot{E}_{c h}\end{array}$ & $\begin{array}{c}\text { Exergy } \\
\dot{E}_{x} \\
{[\mathrm{MW}]}\end{array}$ \\
\hline 1 & Air & 217.1 & 288.0 & 1.013 & 0.000 & 0.290 & 0.290 \\
\hline 2 & Air & 217.1 & 420.8 & 3.440 & 27.24 & 0.290 & 27.53 \\
\hline 2 & Air & 217.1 & 325.4 & 3.280 & 21.66 & 0.290 & 21.95 \\
\hline 3 & Air & 217.1 & 701.6 & 42.00 & 102.8 & 0.290 & 103.1 \\
\hline 4 & Fuel & 3.960 & 288.0 & 45.00 & 2.67 & 176.9 & 179.6 \\
\hline 5 & $\begin{array}{l}\text { Exhaust } \\
\text { gases }\end{array}$ & 221.1 & 1350 & 39.80 & 228.1 & 1.840 & 229.9 \\
\hline 6 & \multicolumn{4}{|c|}{ Power to HPC } & 85.95 & ---- & 85.95 \\
\hline 7 & $\begin{array}{l}\text { Exhaust } \\
\text { gases }\end{array}$ & 221.1 & 1031 & 10.80 & 138.23 & 1.840 & 140.1 \\
\hline 8 & \multicolumn{4}{|c|}{ Power to LPC } & 29.57 & ---- & 29.57 \\
\hline 9 & $\begin{array}{l}\text { Exhaust } \\
\text { gases }\end{array}$ & 221.1 & 918.4 & 6.370 & 107.3 & 1.840 & 109.2 \\
\hline 10 & \multicolumn{4}{|c|}{ Net Power } & 49.37 & ---- & 49.37 \\
\hline 11 & $\begin{array}{l}\text { Exhaust } \\
\text { gases }\end{array}$ & 221.1 & 719.1 & 2.140 & 54.13 & 1.840 & 55.97 \\
\hline
\end{tabular}


2016-07-01

\title{
Exergetic, exergoeconomic and exergoenvironmental analysis of intercooled gas turbine engine
}

\author{
Almutairi, Abdulrahman S. \\ American Institute of Aeronautics and Astronautics
}

\begin{abstract}
Abdulrahman S. Almutairi, Pericles Pilidis, and Nawaf Al-Mutawa. "Exergetic, Exergoeconomic and Exergoenvironmental Analysis of Intercooled Gas Turbine Engine", 52nd AIAA/SAE/ASEE Joint Propulsion Conference, Propulsion and Energy Forum, (AIAA 2016-5060) http://dx.doi.org/10.2514/6.2016-5060 Downloaded from Cranfield Library Services E-Repository
\end{abstract}

